\title{
EVALUATION OF ANTIFUNGAL ACTIVITY OF A 3-EXTRACT FORMULATION IN TOPICAL DOSAGE FORM AND ITS SAFETY ASPECT
}

\author{
ELIN YULINAH SUKANDAR ${ }^{1 *}$, IRDA FIDRIANNY ${ }^{2}$, ERIWAN SUSANTO $^{1}$, DEWI SAFITRI ${ }^{1}$
}

${ }^{1}$ Department of Pharmacology and Clinical Pharmacy, School of Pharmacy, Institut Teknologi Bandung, Bandung, Indonesia. ${ }^{2}$ Department of Pharmaceutical Biology, School of Pharmacy, Institut Teknologi Bandung, Indonesia. Email: elin@fa.itb.ac.id

Received: 18 June 2016, Revised and Accepted: 29 June 2016

\section{ABSTRACT}

Objective: To determine the combination of extract of Rosmarinus officinalis leaves, Zingiber officinale rhizome, and Curcuma xanthorrhiza rhizome in 2 form topical preparations, cream, and ointment, through in situ study, as well as to evaluate safety aspect of both cream and ointment.

Methods: Irritation skin and eye test were performed according to OECD guideline. Rabbits were also used as an object of the in situ study. A suspension of Trichophyton mentagrophytes was injected through the skin on both sides of rabbit's back to induce dermatophytosis. Throughout the treatment period, topical preparation was applied to the infected site until the wound was fully recovered.

Results: There was no significant irritation effect on both topical dosage forms. However, an incidence of redness was observed in the skin applied by cream. Healing rate of extract in ointment.

Conclusion: Combination of the corresponding extract showed antifungal activity and was comparable to that of ketoconazole as a reference drug

Keywords: Rosmarinus officinalis leaves, Zingiber officinale rhizome, Curcuma xanthorrhiza rhizome, In situ, Irritation.

(C) 2016 The Authors. Published by Innovare Academic Sciences Pvt Ltd. This is an open access article under the CC BY license (http://creativecommons. org/licenses/by/4. 0/) DOI: http://dx.doi.org/10.22159/ajpcr.2016.v9s2.13551

\section{INTRODUCTION}

Being located in tropical area, fungus is easily grown and may cause infection. In Indonesia, cutaneous fungal infection itself is commonly found [1]. Besides previous-mentioned factor, there are several factors that cause high prevalence of fungal infection, such as the use of antineoplastics, over usage of broad spectrum antibiotics, use of immunosuppressive agents, opportunistic infection in HIV/AIDS patients, which increased in the scope of parenteral therapy and after natural disasters $[1,2]$

One common type of superficial fungal infection is that caused by dermatophyte such as Trichophyton mentagrophytes and Trichophyton rubrum [3]. In human, the most commonly known infection caused by T. mentagrophytes is named tinea pedis or athlete's foot. It is not only infect human but also animals which manifest as ringworm. Currently, drug of choice of fungal infection is relatively limited and showed intermediate to severe side effects. Thus, effort to look for new agents is increasingly developed to obtained better safety margin with comparable pharmacological effect.

Based on our previous research, administration of rosemary leaves extract, ginger rhizome extract, and Java turmeric rhizome extract possessed antifungal activities, both as single extract administration and as combination. So that, in this study, researchers would like to prove that topical preparation containing corresponding extracts has antifungal activity through in situ study and evaluate its safety aspect as it will be applied in the skin using dermal and ocular irritation test.

\section{METHODS}

\section{Materials and fungal strains}

Selected herbs: Rosemary leaves (Rosmarinus officinalis), ginger (Zingiber officinale) rhizome, and Java turmeric (Curcuma xanthorrhiza) rhizome were collected from several areas in West Java, Indonesia, starting from January to April and determined at herbarium Bandungense, School of Life Science and Technology, Indonesia The fungi used in this study were $T$. mentagrophytes which was provided from Microbiology Laboratory, School of Pharmacy, Institut Teknologi Bandung, Indonesia. The fungi were maintained under standard condition on Sabouraud dextrose agar (SDA). Inoculum of T. mentagrophytes was incubated in $28^{\circ} \mathrm{C}$ for 7 days.

\section{Animals}

Nine male albino rabbits were provided from Lembang, West Java, Indonesia and were kept in Animal Laboratory, School of Pharmacy. Three of them were utilized for in situ study, and all the rest would be included in irritation tests. They were kept under standard condition. No pre-treatment was performed. All procedures conducted in this study followed the OECD document for dermal and ocular irritation test, which is a common protocol in the institution.

Preparation, standardization, and phytochemical screening of extracts

Herbs dried in the oven were pulverized into a powder. It was extracted with ethanol 96\%, three times repeatedly, using reflux method. Subsequently, each extract was concentrated in a rotary evaporator until viscous form was obtained and kept at $4{ }^{\circ} \mathrm{C}$ for further analysis. Standardization was performed on both crude materials and extracts regarding quality control published by the WHO [4]. Qualitative phytochemical screening includes alkaloid, flavonoid, saponin, quinone, tannin, and steroid/triterpenoid.

\section{Culture media and tested extract preparation} Media

SDA and Sabouraud dextrose broth (SDB) were utilized in this study. Approximately $65 \mathrm{~g}$ of SDA was mixed in $1 \mathrm{~L}$ distilled water, whereas $30 \mathrm{~g}$ SDB was solved in the same amount of distilled water. Before the experiment, both media were sterilized by autoclaving at $121^{\circ} \mathrm{C}$ for 15 minutes [5]. Each solution was boiled for about 1 minute.

\section{Tested extract}

Each viscous extract (1638.4 mg) was dissolved in $10 \mathrm{ml}$ dimethyl sulfoxide (DMSO) $100 \%$ as stock solution. This solution was used to 
make a working solution of $16.384 \mu \mathrm{g} / \mathrm{mL}$ in DMSO $10 \%$ after dilution using SDB. Ketoconazole was used as reference drug. About $25.6 \mathrm{mg}$ ketoconazole was dissolved in $10 \mathrm{ml}$ of DMSO 100\%, and it was diluted into $256 \mu \mathrm{g} / \mathrm{ml}$ in DMSO 10\% after diluting by SDB.

Ointment and cream formulation containing rosemary leaves extract, ginger rhizome, and Java turmeric extract

Ointment was made using the following formula: Total extract in combination of $2 \%$, vaseline flavum $90 \%$, and liquid paraffin $10 \%$. It was formulated using fusion method until semisolid mass was formed. Whereas, cream contained $2 \%$ of extracts, $5 \%$ liquid paraffin, $25 \%$ vaseline flavum, $1 \%$ cetomacrogol $1000,4 \%$ cetostearyl alcohol, and add to $100 \%$ by distilled water.

\section{Dermal irritation test}

The procedure of this experiment followed an OECD protocol No. 404 [6]. Shared area on the right on the rabbit's dorsal was applied by the test substance, whereas the other sides were used as control. About $0.5 \mathrm{~g}$ of ointment dosage form and water/oil cream containing selected extracts (rosemary leaves, ginger rhizome, and temulawak rhizome) were applied directly to the area and covered with a gauze patch. The tested substances were exposed for $4 \mathrm{hrs}$, and at the end of the period, residual substances were removed using water. Observation was performed at $1,24,48$, and $72 \mathrm{hrs}$ after gauze removal. The primary irritation index (PII) was classified as the following: $0=$ No irritant, $>0-2$ $=$ Slight irritant, $>2-5=$ Mild irritant, $>5-8=$ Severe irritant (Table 1).

\section{Ocular irritation test}

There were three healthy albino rabbits used in this experiment. The ointment and w/o cream containing extract combination were applied as a single dose to the right eye, and the untreated eye served as the control. Each dosage form (100 mg) was applied on the rabbit's eye. The degree of irritation was evaluated at 1, 24, 48, and $72 \mathrm{hrs}$ after application. Evaluation was made by scoring the lesions in cornea, iris, conjunctiva, and chemosis [7]. Ocular irritation index was classified as: Non-irritant (if the total value equals to 0 ), mild irritant (score is $>0-4$ ), intermediate irritant (>4-8), and severe irritant (>8-13) (Table 2).

\section{Antifungal activities: In situ study}

Approximately $24 \mathrm{hrs}$ before the test, fur was removed using an electric clipper on the dorsal area of the trunk of the animals, and it was divided into two main areas. Fur removal should be conducted carefully to avoid abrading the skin and only animals with healthy skin were used. Each group consisted of three rabbits. A total of $1 \mathrm{ml}$ of T. mentagrophytes suspension was injected through the skin on both sides of rabbit's back to induce dermatophytosis. After $7 \mathrm{hrs}, 0.5 \mathrm{~g}$ of topical dosage forms was applied onto the right site of injection, whereas another one was preserved as control. Infected area of rabbits was then covered by sterile gauze, micropore, plaster, and bandages. Observation was performed throughout the period until the infection was cured. Parameters that were observed included reduction score of erythema and edema score.

Erythema score: 0 = No erythema observed; 1 =Very slight erythema (area of lesion $<10 \mathrm{~mm}$ ); 2 = Well-defined erythema (diameter of lesion were below $10.00-15.00 \mathrm{~mm}$ ); $3=$ moderate to severe (15.00-20.00 mm); 4 = Severe erythema $(>20.00 \mathrm{~mm})$.

Edema score: $0=$ No edema; 1 = Very slight edema (thickness below $1 \mathrm{~mm}$ ); 2 = Slight edema (thickness between 1.00 and $2.00 \mathrm{~mm}$ ); 3 = Moderate edema (between 2.00 and $3.00 \mathrm{~mm}$ ); 4 = Severe edema $(>3.00 \mathrm{~mm})$.

\section{RESULTS}

\section{Phytochemical screening}

According to phytochemical screening, rosemary ( $R$. officinalis), ginger (Z. officinale) rhizome, and Java turmeric (C. xanthorrhiza) rhizome contained flavonoid, phenol, quinone, and steroid/triterpenoid. The result is presented in the Table 3.

\section{Dermal irritation test}

Observation on erythema and edema occurred during experiments were presented in Table 4 (cream) and Table 5 (ointment). Both parameters were calculated to obtain PII for each observation time.

Table 1: Grading of skin reaction on dermal irritation test*

\begin{tabular}{lll}
\hline Erythema formation & Score & Edema formation \\
\hline $\begin{array}{l}\text { No erythema } \\
\begin{array}{l}\text { Very slight erythema (barely } \\
\text { perceptible) }\end{array}\end{array}$ & 1 & $\begin{array}{l}\text { No edema } \\
\text { Very slight edema (barely } \\
\text { perceptible) }\end{array}$ \\
$\begin{array}{l}\text { Well-defined erythema } \\
\text { Moderate to severe erythema }\end{array}$ & 2 & $\begin{array}{l}\text { Slight edema (edges of } \\
\text { area well-defined by } \\
\text { definite raising) } \\
\text { Moderate edema (raised } \\
\text { approximately 1 mm) } \\
\text { Severe edema (raised more } \\
\text { than 1 mm and extending } \\
\text { beyond area of exposure) }\end{array}$ \\
$\begin{array}{l}\text { Severe erythema (beef redness) } \\
\text { to eschar formation preventing } \\
\text { grading of erythema }\end{array}$ & 4 &
\end{tabular}

*Cited from OECD 404 [6]

Table 2: Grading of ocular lesions*

\begin{tabular}{|c|c|c|}
\hline Parameter & Observation & Score \\
\hline \multirow[t]{5}{*}{ Cornea } & No ulceration or opacity & 0 \\
\hline & $\begin{array}{l}\text { Scattered or diffuse areas of opacity (other } \\
\text { than slight dulling of normal luster); details } \\
\text { of iris clearly visible }\end{array}$ & 1 \\
\hline & $\begin{array}{l}\text { Easily discernible translucent area; details of } \\
\text { iris slightly obscured }\end{array}$ & 2 \\
\hline & $\begin{array}{l}\text { Nacreous area; no details of iris visible; size } \\
\text { of pupil barely discernible }\end{array}$ & 3 \\
\hline & $\begin{array}{l}\text { Opaque cornea; iris not discernible through } \\
\text { the opacity }\end{array}$ & 4 \\
\hline \multirow[t]{4}{*}{ Iris } & Normal & 0 \\
\hline & $\begin{array}{l}\text { Markedly deepened rugae, congestion, } \\
\text { swelling, moderate circumcorneal }\end{array}$ & 1 \\
\hline & hyperemia; or injection; iris reactive to light & \\
\hline & $\begin{array}{l}\text { Hemorrhage, gross destruction, or no } \\
\text { reaction to light }\end{array}$ & 2 \\
\hline \multirow{4}{*}{ Conjunctivae } & Normal & 0 \\
\hline & Some blood vessels hyperemic & 1 \\
\hline & $\begin{array}{l}\text { Diffuse, crimson color; individual vessels not } \\
\text { easily discernible }\end{array}$ & 2 \\
\hline & Diffuse beefy red & 3 \\
\hline \multirow[t]{5}{*}{ Chemosis } & Normal & 0 \\
\hline & Some swelling above normal & 1 \\
\hline & Obvious swelling, with partial eversion of lids & 2 \\
\hline & Swelling, with lids about half closed & 3 \\
\hline & Swelling, with lids more than half closed & 4 \\
\hline
\end{tabular}

${ }^{*}$ Cited from OECD 405 [7]

Table 3: The results of phytochemical screening

\begin{tabular}{llll}
\hline Parameters & \multicolumn{2}{l}{ Result } & \\
\cline { 2 - 4 } & $\begin{array}{l}\text { Rosemary } \\
\text { (Crude }\end{array}$ & $\begin{array}{l}\text { Ginger } \\
\text { (Crude }\end{array}$ & $\begin{array}{l}\text { Java turmeric } \\
\text { (Crude } \\
\end{array}$ \\
& Extract) & Extract) & Extract) \\
& $-/-$ & $-/-$ & $-/-$ \\
Alkaloid & $+/+$ & $+/+$ & $+/+$ \\
Flavonoid & $-/-$ & $-/-$ & $-/-$ \\
Tannin & $+/+$ & $+/+$ & $+/+$ \\
Phenol & $-/-$ & $-/-$ & $-/-$ \\
Saponin & $+/+$ & $+/+$ & $+/+$ \\
Quinon & $+/+$ & $+/+$ & $+/+$ \\
Steroid/triterpenoid & + & & \\
\hline
\end{tabular}


Table 4: PII after application of cream contained 2\% extracts

\begin{tabular}{|c|c|c|c|c|c|c|c|c|}
\hline \multirow[t]{3}{*}{ Rabbit number } & \multicolumn{8}{|c|}{ Observation time after dosage form being applied } \\
\hline & \multicolumn{2}{|l|}{$1 \mathrm{hr}$} & \multicolumn{2}{|l|}{24 hrs } & \multicolumn{2}{|l|}{$48 \mathrm{hrs}$} & \multicolumn{2}{|l|}{72 hrs } \\
\hline & Erythema & Edema & Erythema & Edema & Erythema & Edema & Erythema & Edema \\
\hline 1 & 0 & 0 & 0 & 0 & 0 & 0 & 0 & 0 \\
\hline 2 & 0 & 0 & 0 & 0 & 0 & 0 & 0 & 0 \\
\hline 3 & 0 & 0 & 0 & 0 & 0 & 0 & 0 & 0 \\
\hline Average & 0 & 0 & 0 & 0 & 0 & 0 & 0 & 0 \\
\hline Total & 0 & & 0 & & 0 & & 0 & \\
\hline
\end{tabular}

PII: Primary irritation index

Table 5: PII after application of ointment contained $2 \%$ extracts

\begin{tabular}{|c|c|c|c|c|c|c|c|c|}
\hline \multirow[t]{3}{*}{ Rabbit number } & \multicolumn{8}{|c|}{ Observation time after dosage form being applied } \\
\hline & \multicolumn{2}{|l|}{$1 \mathrm{hr}$} & \multicolumn{2}{|l|}{24 hrs } & \multicolumn{2}{|l|}{48 hrs } & \multicolumn{2}{|l|}{$72 \mathrm{hrs}$} \\
\hline & Erythema & Edema & Erythema & Edema & Erythema & Edema & Erythema & Edema \\
\hline 1 & 0 & 0 & 0 & 0 & 0 & 0 & 0 & 0 \\
\hline 2 & 0 & 0 & 0 & 0 & 0 & 0 & 0 & 0 \\
\hline 3 & 0 & 0 & 0 & 0 & 0 & 0 & 0 & 0 \\
\hline Average & 0 & 0 & 0 & 0 & 0 & 0 & 0 & 0 \\
\hline
\end{tabular}

PII: Primary irritation index

Table 6: Ocular irritation score after ointment contained 2\% extracts being applied

\begin{tabular}{llllll}
\hline \multirow{2}{*}{$\begin{array}{l}\text { Rabbit } \\
\text { number }\end{array}$} & $\begin{array}{l}\text { Observed } \\
\text { at (hrs) }\end{array}$ & \multicolumn{2}{l}{ Response } & & \\
\cline { 3 - 6 } & & Opacity & Iris & Conjunctivae & Chemosis \\
\hline 1 & 1 & 0 & 0 & 0 & 0 \\
& 24 & 0 & 0 & 0 & 0 \\
& 48 & 0 & 0 & 0 & 0 \\
& 72 & 0 & 0 & 0 & 0 \\
2 & 1 & 0 & 0 & 0 & 0 \\
& 24 & 0 & 0 & 0 & 0 \\
& 48 & 0 & 0 & 0 & 0 \\
3 & 72 & 0 & 0 & 0 & 0 \\
& 1 & 0 & 0 & 0 & 0 \\
& 24 & 0 & 0 & 0 & 0 \\
& 48 & 0 & 0 & 0 & 0 \\
Average & 0 & 0 & 0 & 0 & 0 \\
Total & 0 & 0 & 0 & 0 & \\
\hline
\end{tabular}

Table 7: Ocular irritation score after cream contained 2\% extracts being applied

\begin{tabular}{|c|c|c|c|c|c|}
\hline \multirow{2}{*}{$\begin{array}{l}\text { Rabbit } \\
\text { number }\end{array}$} & \multicolumn{5}{|l|}{ Response } \\
\hline & $\begin{array}{l}\text { Observed } \\
\text { at (hrs) }\end{array}$ & Opacity & Iris & Conjunctivae & Chemosis \\
\hline \multirow[t]{4}{*}{1} & 1 & 0 & 0 & 1 & 0 \\
\hline & 24 & 0 & 0 & 0 & 0 \\
\hline & 48 & 0 & 0 & 0 & 0 \\
\hline & 72 & 0 & 0 & 0 & 0 \\
\hline \multirow[t]{4}{*}{2} & 1 & 0 & 0 & 0 & 0 \\
\hline & 24 & 0 & 0 & 0 & 0 \\
\hline & 48 & 0 & 0 & 0 & 0 \\
\hline & 72 & 0 & 0 & 0 & 0 \\
\hline \multirow[t]{5}{*}{3} & 1 & 0 & 0 & 0 & 0 \\
\hline & 24 & 0 & 0 & 0 & 0 \\
\hline & 48 & 0 & 0 & 0 & 0 \\
\hline & 72 & 0 & 0 & 0 & 0 \\
\hline & 0 & 0 & 0.083 & 0 & \\
\hline Total & 0.083 & & & & \\
\hline
\end{tabular}

\section{Ocular irritation test}

To complete antifungal potency of extract in situ, dermal and ocular irritation test were performed. As the result, there was no severe irritation effect of both dosage forms containing extracts. However, in ocular irritation test, cream was irritated rabbit's eye mildly. The results of this experiment were presented in Tables 6 and 7.

In situ study of antifungal activity of a 3-extracts formulation

The ointment and cream already prepared were utilized in this study to observe its activity in situ. As a reference drug, we used ketoconazole $2 \%$ cream. Wound healing rate, erythema, and edema score were represented in Table 8 and Figs. 1 and 2.

According to edema and erythema score, at day 6, there was a significant difference between ketoconazole cream and positive control. The scores of cream containing extracts were differed remarkably compare to control at day 8 , whereas that of ointment showed a difference at day 11. Based on wound healing period, there was no distinction between ointment extract (22.67 days) and control (24 days). Thus, we can conclude that ointment containing extracts did not demonstrate antifungal activity but that of cream containing extracts was relatively the same with that of ketoconazole cream as a reference drug.

\section{DISCUSSION}

Our previous studies (unpublished) have proven that ethnopharmacological based herbs including rosemary leaves, ginger rhizome, and Java turmeric rhizome possessed antifungal activity against three strains of fungi: Candida albicans, T. mentagrophytes, and Microsporum gypseum, either alone, 2-extract-combination, or 3-extract-combination through in vitro study. In this study, we would like to observe further the activity of three extracts in combination by formulating them into topical dosage forms: Cream and ointment. As fungal infection affects the skin and connected area, topical preparation is the best form to be developed. It has several functions such as more occlusive leading to better penetration as it intact directly to the infected area for a certain period; it acts locally without minimal exhibit systemic absorption thus it may prevent the systemic adverse effect.

Two types of specific toxicity test were carried out to evaluate irritation potential of a topical preparation containing three extracts, both implication of dosage form in ocular and dermal test. The results 
Table 8: Wound healing rate

\begin{tabular}{ll}
\hline Group & Wound healing rate (days) \\
\hline Ketoconazole cream $2 \%$ & $14.33 \pm 1.53$ \\
Extracts cream $2 \%$ & $16.67 \pm 1.16$ \\
Extracts ointment $2 \%$ & $22.67 \pm 1.16$ \\
Positive control & $24.00 \pm 2.35$ \\
\hline
\end{tabular}

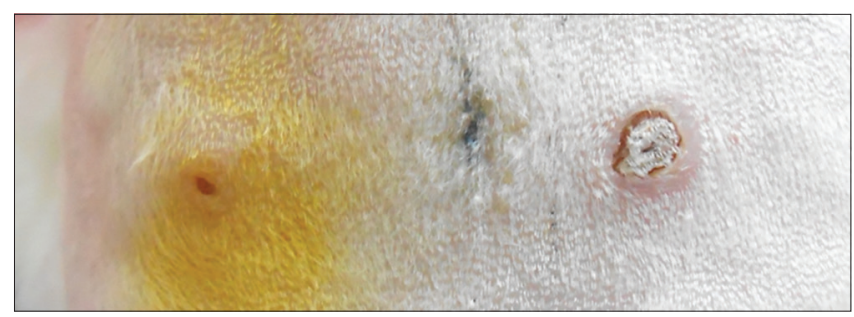

Fig. 1: Comparative wound healing result between tested substance cream $2 \%$ (left), and positive control (right)

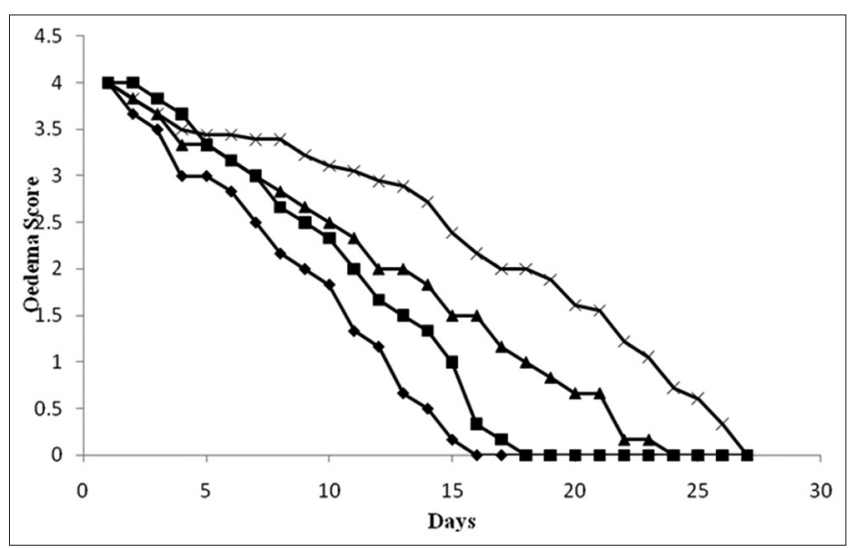

Fig. 2: Profile of score reduction during treatment period. $(\diamond)$

ketoconazole cream 2\%, ( $\square$ ) cream containing extracts, ( $\square$ ) ointment containing extracts, $(\times)$ control

showed that there was no irritant effect of ointment to neither skin nor eyes, meanwhile ointment was mildly irritating (PII of 0.083). Since we used several components in the formulation, we suggest that there is a component(s) that irritant. Cetomacrogol 100, which is one of ingredients in the cream dosage form, is relatively irritant to skin, eyes, mucous membranes, and respiratory system [8]. In the cream formulation, cetomacrogol 1000 made up to $1 \%$. In addition, cetostearyl alcohol also contributed to the irritant effect. A similar result was obtained while a cream containing $3 \%$ cetostearyl alcohol was able to abrade rabbit skin after being applied for 5 days consecutively [9].

According to in situ study, we would like to investigate antifungal activity of cream and ointment containing extract against T. mentagrophytes. The activity was determined though wound retraction, erythema and edema score which were evaluated throughout the period until the wound was fully recovered. Variation on healing happened perhaps due to several factors, such as immunity response from each rabbit toward active compounds and a basis. In ointment, lipophilic compounds will detain in the ointment due to the similar polarity with vehicle, whereas hydrophilic compound will detach easily and be transported to the skin as long as the preparation is directly contacted. The similar mechanism occurs in the cream preparation. Indeed, we believe that it is more likely that major compounds in extract are lipophilic. Lipophilic compound will be longer attached to the ointment basis, thus it is considerably difficult for lipophilic compound to move from basis to the skin. Whereas, some lipophilic compound will be no longer detain in water- soluble based of cream leading to ease of transport of active compound from basis to the skin. The more active compounds transported to the skin, the better pharmacological effect will be obtained. Due to this transportation scheme, skin treated by cream containing extract is better in curing the infection. However, according to the results of phytochemical screening that almost all secondary metabolites exist in the ethanolic extracts of all herbs are relatively polar, except that of steroid/triterpenoid compound.

Z. officinale is a perennial plant that is used not only as food and beverages due to its better pleasant and aroma [10] but also is utilized for treating several diseases either empirically and scientifically. For instance, digestive disorder, hypertension, inflammation, and cold are common diseases where ginger can be used [11]. The marker compounds contained in ginger, particularly gingerol and shogaol, have been reported exhibit important antioxidant properties with remarkable anticancer, and antimutagenic effect [12], analgesic [13], inhibit melanoma [11], inhibit platelet aggregation [14], antihyperlipidemia [15], antidiabetes [16], ameliorate renal and pancreas damage [17], and so on. Certain compounds contained in (Z. officinale) demonstrate synergistic effect as auxiliary chemical agent against on C. albicans, Enterococcus faecalis, Escherichia coli, and their endotoxins [18] and also other microbes [19].

Rosemary ( $R$. officinalis) contains several polyphenol compound such as carnosic acid, carnosol, 12-0-methylcarnosic acid (phenolic diterpenes), rosmarinic acid (caffeoyl compound), genkwanin, and isoscutellarein 7-0-glucoside (flavones) [20]. Genena reported that rosemary extract has antioxidant properties which may be contributed in preventing bacterial growth such as Staphylococcus aureus, Bacillus cereus, Pseudomonas aeruginosa, and C. albicans [21]. Meanwhile, Java turmeric (C. xanthorrhiza) has curcuminoids and xanthorrhizol as a marker. It was reported having broad pharmacological effect such as immunomodulator [22], anticandidal [23], antinociceptive [24], improve serum level of glucose, triglyceride, fatty acid, and bile acid secretion [25].

\section{REFERENCES}

1. Budimulja U. Mycotic diseases in Indonesia. Kor J Med Mycol 1999;4(1):1-5.

2. Benedict $\mathrm{K}$, Park BJ. Invasive fungal infections after natural disasters. Emerg Infect Dis 2014;20(3):349-55.

3. Tawfik AA, Noaman I, El-Elsayyad H, El-Mashad N, Soliman M. A study of the treatment of cutaneous fungal infection in animal model using photoactivated composite of methylene blue and gold nanoparticle. Photodiagnosis Photodyn Ther 2016. pii: S1572-1000(16):30083-7.

4. WHO. Quality Control Methods for Medicinal Plant Materials. Geneva: WHO Library Cataloguing in Publication Data; 1998.

5. Power DA, Peggy JM. Manual of BBL Products and Laboratory Procedures. $6^{\text {th }}$ ed. New York: Becton Dickinson and Co.; 1988. p. 226,338 .

6. OECD. Test No. 404: Acute Dermal Irritation/Corrosion, OECD Guideline for the Testing of Chemicals. Paris: OECD Publishing; 2002.

7. OECD. Test No. 405: Acute Eye Irritation/Corrosion, OECD Guideline for the Testing of Chemicals. Paris: OECD Publishing; 2012.

8. Material Safety Data Sheet of Cetomacrogol 1000 according to 91/155/ EEC - ISO 11014-1. SDS No. 10366. Pharmaniaga; 2006. p. 1-4.

9. Elder RL. Final report on the safety assessment of cetearyl alcohol, cetyl alcohol, isostearyl alcohol, myristyl alcohol, and behenyl alcohol. J Am Coll Toxicol 1988;7(3):359-413.

10. Ishaaya I, Horowitz AR. In: Ishaaya I, Degheele D, editors. Insecticides with Novel Modes of Action: An Overview, in Insecticides with Novel Modes of Action. New Delhi: Narosa Publishing House; 1998. p. 1-24.

11. Cojocaru SI, Stan M, Stoian G, Dinischiotu A. effects of Zingiber officinale roscoe fresh extract on amelanotic melanoma and normal skin fibroblasts. Rev Med Chir Soc Med Nat Iasi 2015;119(2):592-6.

12. Karna P, Chagani S, Gundala SR, Rida PC, Asif G, Sharma V, et al. Benefits of whole ginger extract in prostate cancer. Br J Nutr 2012;107(04):473-84.

13. Wilson PB. Ginger (Zingiber officinale) as an analgesic and 
ergogenic aid in sport: A systemic review. J Strength Cond Res 2015;29(10):2980-95

14. Marx W, McKavanagh D, McCarthy AL, Bird R, Ried K, Chan A, et al. The effect of ginger (Zingiber officinale) on platelet aggregation: A systematic literature review. PLoS One 2015;10(10):e0141119.

15. Ebrahimzadeh Attari V, Ostadrahimi A, Asghari Jafarabadi M, Mehralizadeh S, Mahluji S. Changes of serum adipocytokines and body weight following Zingiber officinale supplementation in obese women: A RCT. Eur J Nutr. 2015.

16. Li Y, Tran VH, Duke CC, Roufogalis BD. Gingerols of Zingiber officinale enhance glucose uptake by increasing cell surface GLUT4 in cultured L6 myotubes. Planta Med 2012;78(14):1549-55.

17. Kazeem MI, Akanji MA, Yakubu MT. Amelioration of pancreatic and renal derangements in streptozotocin-induced diabetic rats by polyphenol extracts of ginger (Zingiber officinale) rhizome Pathophysiology 2015;22(4):203-9.

18. Valera MC, Maekawa LE, Chung A, Cardoso FG, Oliveira LD, Oliveira CL, et al. The effect of sodium hypochlorite and ginger extract on microorganisms and endotoxins in endodontic treatment of infected root canals. Gen Dent 2014;62(3):25-9.

19. Azizi A, Aghayan S, Zaker S, Shakeri M, Entezari N, Lawaf S. In vitro effect of Zingiber officinale extract on growth of Streptococcus mutans and Streptococcus sanguinis. Int J Dent 2015;2015:489842.
20. Frankel EN, Huang SW, Aeschbach R, Prior E. Antioxidant activity of a rosemary extract and its constituents, carnosic acid, carnosol, and rosmarinic acid, in bulk oil and oil-in-water emulsion. J Agric Food Chem 1996;44(1):131-5.

21. Genena AK, Hense H, Smânia A Jr, Souza SM. Rosemary (Rosmarinus officinalis): A study of the composition, antioxidant and antimicrobial activities of extracts obtained with supercritical carbon dioxide. Food Sci Technol (Campinas) 2008;28(2):463-9.

22. Kim AJ, Kim YO, Shim JS, Hwang JK. Immunostimulating activity of crude polysaccharide extract isolated from Curcuma xanthorrhiza Roxb. Biosci Biotechnol Biochem 2007;71(6):1428-38.

23. Rukayadi Y, Yong D, Hwang JK. In vitro anticandidal activity of xanthorrhizol isolated from Curcuma xanthorrhiza Roxb. J Antimicrob Chemother 2006;57(6):1231-4.

24. Devaraj S, Esfahani AS, Ismail S, Ramanathan S, Yam MF. Evaluation of the antinociceptive activity and acute oral toxicity of standardized ethanolic extract of the rhizome of Curcuma xanthorrhiza Roxb. Molecules 2010;15(4):2925-34

25. Yasni S, Imaizumi K, Sugano M. Effects of an Indonesian medicinal plant, Curcuma xanthorrhiza Roxb., on the levels of serum glucose and triglyceride, fatty acid desaturation, and bile acid excretion in streptozotocin-induced diabetic rats. Agric Biol Chem 1991;55(12):3005-10 